\title{
Health-related quality of life in type I and type 2 diabetic patients in a Portuguese central public hospital
}

This article was published in the following Dove Press journal:

Diabetes, Metabolic Syndrome and Obesity: Targets and Therapy

29 April 2015

Number of times this article has been viewed

\section{Eduardo Sepúlveda ${ }^{1,2}$ \\ Rui Poínhos ${ }^{2,3}$ \\ Miguel Constante 4,5 \\ José Pais-Ribeiro ${ }^{1,2}$ \\ Paula Freitas 6,7 \\ Davide Carvalho 6,7 \\ 'Faculty of Psychology and} Educational Sciences, University of Porto, Porto, Portugal; ${ }^{2}$ Associação de Prevenção e Apoio à Diabetes, Porto, Portugal; ${ }^{3}$ Faculty of Nutrition and Food Sciences, University of Porto, Porto, Portugal; ${ }^{4}$ Institute of Psychiatry, King's College London, London, UK; ${ }^{5}$ Department of Psychiatry, Hospital Beatriz Ângelo, Loures, Portugal; ${ }^{6}$ Department of Endocrinology, Diabetes and Metabolism, Centro Hospitalar São João, Porto, Portugal; ${ }^{7}$ Faculty of Medicine, University of Porto, Porto, Portugal
Correspondence: Eduardo Sepúlveda Faculty of Psychology and Educational Sciences, University of Porto, Rua Alfredo Allen, s/n, 4200-I 35 Porto, Portugal

Email edusepulvedamoura@gmail.com
Background: Diabetes mellitus is a chronic metabolic disease, the prevalence of which has registered a considerable increase, mainly in adults and elderly. The purpose of this study was to assess the relationship between health-related quality of life in patients with diabetes and sex, body mass index, type of diabetes and treatment regimens (type 1 diabetes: intensive versus conventional treatment; type 2 diabetes: insulin use versus non-insulin use), and duration of diabetes.

Methods: One hundred and twenty-four patients with diabetes were interviewed. Health-related quality of life was evaluated using the age-adjusted Short-Form 36 dimensions (physical functioning, role-physical, bodily pain, general health, vitality, social functioning, role-emotional, and mental health), and related to demographic and clinical variables. Independent samples $t$-tests and One-Way Analysis of Variance were used to compare means of independent samples. The degree of association between pairs of variables was measured by Pearson's $(r)$ or Spearman's $(r)$ correlation coefficients.

Results: The mean age of the study population was $55.7 \pm 16.4$ years; $54.8 \%$ were male, and $77.4 \%$ had type 2 diabetes. Females reported worse quality of life than males in all dimensions of the Short-Form 36, except for role-physical and bodily pain. Obese patients had worse physical functioning than normal weight and overweight patients, and worse vitality than their normal weight counterparts. Type 2 diabetic patients taking insulin had lower physical functioning and vitality than those without insulin therapy. Longer duration of diabetes was associated with lower physical functioning, role-physical, general health, vitality, role-emotional, and mental health.

Conclusion: Being female, obese, having type 2 diabetes and taking insulin, and having a longer disease duration are characteristics associated with worse age-adjusted quality of life in patients with diabetes.

Keywords: clinical variables, demographic variables, diabetes mellitus, health-related quality of life

\section{Introduction}

According to the International Diabetes Federation, the worldwide prevalence of adults with diabetes mellitus (DM) is $8.3 \%$, accounting for approximately 382 million people. ${ }^{1}$ In the People's Republic of China, the prevalence of DM in adults aged 20 years or older has increased to $9.7 \%$, accounting for 92.4 million adults with DM. ${ }^{2}$ With regard to the association between family history risk categories and prevalence of DM in Chinese adults aged 20 years or older and living in the People's Republic of China, the prevalence has reached $32.7 \%, 20.1 \%$, and $8.4 \%$, representing at least two 
generations and one generation of first-degree relatives with DM, and no first-degree relatives with DM, respectively. ${ }^{3}$

With the same tendency, the prevalence of type 2 DM has also increased sharply among Chinese immigrants in the USA, so a relevant and interesting conceptual model of type 2 DM self-management was designed and developed by a group of researchers from the People's Republic of China and the USA for this specific group of individuals. This model has seven interrelated factors, ie, sociodemographic characteristics, behavioral and psychological characteristics, social support, linguistic barriers, cultural characteristics, type 2 DM self-management behaviors, and diabetes-related health outcomes (eg, health-related quality of life [HRQoL], $\mathrm{HbA}_{1 \mathrm{c}}$, blood pressure, and other cardiovascular risk factors), and postulates that the first five components have an influence on type 2 DM self-management, and that all factors except for the latter predict health outcomes. ${ }^{4}$ In Portugal, the prevalence of DM in people aged between 20 and 79 years has reached a worrying rate of $11.7 \% .^{5}$

HRQoL aggregates the individual's subjective perception of physical, emotional, and social well-being, ${ }^{6-9}$ includes a cognitive and emotional component, ${ }^{9}$ and is becoming increasingly important for those providing health care for diabetic patients. ${ }^{10,11}$

Concerning the relationship between age, sex, body mass index (BMI), different treatment regimens of type 1 and type 2 patients, disease duration, and HRQoL in patients with DM, the studies have not been consistent, so it is important to evaluate the relationships between these factors and HRQoL.

To our knowledge, the research carried out in Portugal that evaluated the effect of certain demographic and clinical variables on HRQoL in patients with DM did not make the adjustment of HRQoL scores for age, despite the fact that they can mediate some of these relationships. Most studies have found that older age is related to worse HRQoL in DM patients. ${ }^{12-25}$ However, one study ${ }^{26}$ reported that older age of diabetic patients was related to better HRQoL, whereas Fal et $\mathrm{al}^{7}$ did not find a relationship between age and HRQoL. Other studies ${ }^{27-29}$ found that older age in diabetic patients was related to worse and better HRQoL in different dimensions. Diabetic males had better HRQoL ${ }^{12-14,16,21-24,29-32}$ than females. Nevertheless, some studies ${ }^{7,19,20,25,33}$ did not find any relationship between sex and HRQoL in diabetic patients.

Concerning the relationship between BMI and HRQoL in DM, most of the studies have shown that patients with higher BMI had worse HRQoL. 16,20,21,23,28,34,35 However, Mier et $\mathrm{al}^{36}$ did not find a relationship between BMI and HRQoL in type 2 diabetic patients. As far as we know, there are no studies conducted in Portugal that have evaluated the relationship between HRQoL and BMI in individuals with DM. According to two meta-analyses of randomized controlled trials that studied the effect of weight loss on HRQoL, positive clinical changes in BMI do not always produce a gain in HRQoL. ${ }^{37,38}$

With regard to the relationship between type of DM and HRQoL, some studies ${ }^{22,39,40}$ found that type 2 DM was related to worse HRQoL than type $1 \mathrm{DM}$, while other authors ${ }^{30,41}$ found no relationship between type of DM and HRQoL. Trief et $\mathrm{al}^{27}$ found that type $2 \mathrm{DM}$ was related to poor and better HRQoL in the different domains than type $1 \mathrm{DM}$. Another study ${ }^{33}$ found that patients with type 2 DM reported better HRQoL in one dimension of the Short-Form 36 than patients with type $1 \mathrm{DM}$, whereas in other dimensions of this generic tool assessing HRQoL, the two groups of patients did not differ.

Results of research on the relationship between treatment regimens in type 2 diabetic patients and HRQoL have found that insulin therapy was related to lower HRQoL. ${ }^{16,18,19,28,34,36,42}$ Nevertheless, two studies ${ }^{17,26}$ reported an absence of a relationship between type of therapeutic regimen in type 2 DM and HRQoL, while two studies ${ }^{7,33}$ found that patients with type 2 diabetes treated with insulin had poor and better HRQoL in the different domains than those receiving oral hypoglycemic agents.

Concerning the relationship between treatment regimens in type $1 \mathrm{DM}$ and HRQoL, one study ${ }^{22}$ found that type 1 patients on a conventional insulin regimen reported worse HRQoL than those on an intensive insulin regimen. However, other study ${ }^{43}$ reported no relationship between treatment regimen in type $1 \mathrm{DM}$ and HRQoL.

Finally, some studies looking at the relationship between duration of DM and HRQoL have shown that a longer duration of the disease was related to lower HRQoL; ;0,22,23,32,36 however, others ${ }^{7,12,16,26,33}$ found no relationship between diabetes duration and HRQoL, and one ${ }^{43}$ found that an increased duration of DM was related to better HRQoL.

In summary, studies that have investigated the relationship between demographic and medical variables have used a wide range of methods ${ }^{6}$ and questionnaires ${ }^{44}$ to assess HRQoL, and have covered different aspects of HRQoL. These differences may contribute to the discrepancy between study results, and undermines the discussion of our present results.

Given the discrepancies found in the literature, and the lack of studies assessing HRQoL in Portuguese diabetic patients, the aim of this cross-sectional study was to assess 
the relationship between HRQoL and age, sex, BMI, type of $\mathrm{DM}$ and treatment regimens, and duration of DM.

\section{Subjects and methods}

A consecutive sample of 124 patients from the Outpatient Department of Endocrinology, Diabetes and Metabolism, Centro Hospitalar São João, Porto, Portugal, was recruited. Patients were included in the study if they had a diagnosis of type 1 or type 2 DM, were at least 18 years old, and were not currently pregnant. The protocol for the study was approved by the Ethics Committee for Health at the Centro Hospitalar São João, and informed consent was obtained from all participants before participation in the study.

BMI was calculated from participants' self-reported heights and weights. BMI was expressed as weight (in kilograms) divided by the square of height (in meters), and categorized according to the World Health Organization $^{45}$ as "normal weight" (18.5-24.9 kg/m²), "overweight" $\left(25-29.9 \mathrm{~kg} / \mathrm{m}^{2}\right)$, or "obesity" ( $\left.\geq 30 \mathrm{~kg} / \mathrm{m}^{2}\right)$. Treatment regimens for type $1 \mathrm{DM}$ were classified as "conventional treatment" (one or two daily administrations of insulin) or "intensive treatment" (at least three daily administrations of insulin). Type $2 \mathrm{DM}$ patients were classified as on "oral hypoglycemic agents" or "insulin therapy" (the latter including patients only on insulin therapy or on oral hypoglycemic agents plus insulin therapy). Duration of DM was categorized as "less than 10 years", "10-19 years", or "20 years or more".

One questionnaire was designed to collect demographic and clinical data. General HRQoL was assessed by the Portuguese version of the Medical Outcomes Study 36-Item Short-Form Health Survey (SF-36). ${ }^{46,47}$ The eight domains used to assess HRQoL in this analysis were: physical functioning, role-physical, bodily pain, general health, vitality, social functioning, role-emotional, and mental health. Raw dimension scores were transformed to scales ranging from 0 to 100 , in which higher scores indicate higher HRQoL. Given the relationship between age and HRQoL, we adjusted our SF-36 results to the age of the participants; therefore, all other variables were related to the residuals of simple linear regression models having each dimension as a dependent variable and age as the independent variable. All questionnaires were administered by one of the researchers.

Statistical Package for the Social Sciences version 20.0 for Windows software (IBM Corporation, Armonk, NY, USA) was used for the analysis. Descriptive statistical analysis included calculation of means and standard deviations for cardinal variables, and frequencies for ordinal and nominal variables. Independent samples $t$-tests and One-Way Analysis of Variance were used to compare means of independent samples; when significant differences were observed using analysis of variance, we performed multiple comparisons for observed means using the Bonferroni correction. The degree of association between pairs of variables was measured by Pearson's $(r)$ or Spearman's $\left(r_{s}\right)$ correlation coefficients. Chi-square tests were used to determine the dependency between pairs of variables. Relationships were considered to be statistically significant at $P<0.05$.

\section{Results}

Demographic and diabetes-related data are presented in Table 1 . We interviewed 124 patients with DM aged 18-80 years. Most patients were male, had type $2 \mathrm{DM}$, had had the disease for 10 years or more, and were overweight or obese. Table 2 summarizes the demographic and clinical characteristics of the patients. Women had the longest duration of DM and a higher prevalence of obesity. Type 2 patients and overweight patients were older than the other patients.

The average values obtained by patients in the eight dimensions of the SF-36 are shown in Table 3, as well the relationship between these scores and age. There was an association between age and six of the eight dimensions of the SF-36: increased age was associated with worse HRQoL in terms of physical functioning, role-physical, bodily pain, vitality, social functioning, and role-emotional. Physical functioning was the dimension showing the strongest relationship with age.

Table I Demographic and clinical characteristics of patients

\begin{tabular}{|c|c|}
\hline \multicolumn{2}{|l|}{ Sex } \\
\hline Male n (\%) & $68(54.8)$ \\
\hline Female n (\%) & $56(45.2)$ \\
\hline \multicolumn{2}{|l|}{ Age (years) } \\
\hline Whole sample, mean (SD) & $55.7(16.4)$ \\
\hline Type I DM, mean (SD) & $32.8(13.9)$ \\
\hline Type 2 DM, mean (SD) & $62.4(9.6)$ \\
\hline \multicolumn{2}{|l|}{ Type of treatment regimens } \\
\hline Type I DM conventional treatment $\mathrm{n}(\%)$ & I4 (I I.3) \\
\hline Type I DM intensive treatment $\mathrm{n}(\%)$ & |4 (| I.3) \\
\hline Type 2 DM without insulin therapy n (\%) & $50(40.3)$ \\
\hline Type 2 DM on insulin therapy n (\%) & $46(37.1)$ \\
\hline \multicolumn{2}{|l|}{ Duration of DM (years) } \\
\hline$<10, \mathrm{n}(\%)$ & 47 (37.9) \\
\hline $10-19, \mathrm{n}(\%)$ & $39(3 \mid .5)$ \\
\hline$\geq 20, \mathrm{n}(\%)$ & $38(30.6)$ \\
\hline \multicolumn{2}{|l|}{ Body mass index category $\left(\mathrm{kg} / \mathrm{m}^{2}\right)$} \\
\hline $\mid 8.5 \leq \mathrm{BMl}<25.0, \mathrm{n}(\%)$ & $34(27.4)$ \\
\hline $25.0 \leq \mathrm{BMl}<30.0, \mathrm{n}(\%)$ & $46(37.1)$ \\
\hline $\mathrm{BMI} \geq 30.0, \mathrm{n}(\%)$ & $44(35.5)$ \\
\hline
\end{tabular}

Abbreviations: DM, diabetes mellitus; SD, standard deviation. 
Table 2 Relationships between demographic and clinical characteristics of patients

\begin{tabular}{|c|c|c|c|c|c|}
\hline & \multicolumn{3}{|l|}{ Sex } & \multicolumn{2}{|l|}{ Age } \\
\hline & \multirow{2}{*}{$\frac{\text { Male }}{\mathrm{n}(\% \text { within sex) }}$} & \multirow{2}{*}{$\frac{\text { Female }}{\text { n (\% within sex) }}$} & \multirow[t]{2}{*}{$P$-value } & \multirow[t]{2}{*}{ Mean (SD) } & \multirow[t]{2}{*}{$P$-value } \\
\hline & & & & & \\
\hline \multicolumn{6}{|l|}{ Type of treatment regimens } \\
\hline Type I DM conventional treatment $(n=14)$ & $7(10.3)$ & $7(12.5)$ & 0.070 & $39.5(14.9)^{a *}$ & $<0.001$ \\
\hline Type I DM intensive treatment $(n=\mid 4)$ & $8(11.8)$ & $6(10.7)$ & & $26.1(9.0)^{b *}$ & \\
\hline Type 2 DM without insulin therapy $(n=50)$ & $34(50.0)$ & $16(28.6)$ & & $62.2(9.8)^{c *}$ & \\
\hline Type 2 DM on insulin therapy $(n=46)$ & $19(27.9)$ & $27(48.2)$ & & $62.7(9.5)^{c *}$ & \\
\hline \multicolumn{6}{|l|}{ Duration of DM (years) } \\
\hline$<10(n=47)$ & $34(50.0)$ & $13(23.2)$ & 0.009 & $56.3(16.3)$ & 0.251 \\
\hline $10-19(n=39)$ & $18(26.5)$ & $21(37.5)$ & & $52.4(17.4)$ & \\
\hline$\geq 20(n=38)$ & $16(23.5)$ & $22(39.3)$ & & $58.5(15.2)$ & \\
\hline \multicolumn{6}{|l|}{ Body mass index $\left(\mathrm{kg} / \mathrm{m}^{2}\right)$} \\
\hline $\mid 8.5 \leq \mathrm{BMI}<25.0(\mathrm{n}=34)$ & $19(27.9)$ & $15(26.8)$ & 0.013 & $43.8(20.7)^{a *}$ & $<0.001$ \\
\hline $25.0 \leq \mathrm{BMI}<30.0(\mathrm{n}=46)$ & $32(47.1)$ & $14(25.0)$ & & $60.7(12.2)^{\mathrm{b} *}$ & \\
\hline $\mathrm{BMI} \geq 30.0(\mathrm{n}=44)$ & $17(25.0)$ & $27(48.2)$ & & $59.8(11.4)^{\mathrm{b} *}$ & \\
\hline
\end{tabular}

Note: *Presence of the same letter $\left({ }^{(a, b, c}\right)$ in superscript indicates absence of significant differences in post hoc tests. Abbreviations: DM, diabetes mellitus; SD, standard deviation.

The age-adjusted scores of HRQoL by sex are shown in Table 4, BMI class in Table 5, and type of DM and treatment regimens in Table 6.

Diabetic women had worse HRQoL in terms of physical functioning, general health, vitality, social functioning, role-emotional, and mental health than men, and evidenced a tendency in the same direction in terms of role-physical and bodily pain.

Obese patients had lower HRQoL in terms of physical functioning when compared with normal and overweight patients, and reported worse vitality than normal weight patients.

Type 2 patients on insulin therapy had worse physical functioning and vitality than type 2 patients only on oral hypoglycemic agents. Globally, type 2 patients taking insulin tended to show poorer HRQoL than patients in

Table 3 Health-related quality of life in patients with DM and its association with age

\begin{tabular}{|c|c|c|}
\hline \multirow[t]{2}{*}{$\begin{array}{l}\text { SF-36 } \\
\text { dimensions }\end{array}$} & \multirow{2}{*}{$\begin{array}{l}\text { Percent } \\
\text { Mean (SD) }\end{array}$} & \multirow{2}{*}{$\begin{array}{l}\text { Association } \\
\text { with age } \\
r(P \text {-value })\end{array}$} \\
\hline & & \\
\hline Physical functioning & $41.9(37.1)$ & $-0.536(<0.001)$ \\
\hline Role-physical & $39.3(48.6)$ & $-0.286(0.001)$ \\
\hline Bodily pain & $45.1(33.8)$ & $-0.312(<0.00 \mathrm{I})$ \\
\hline General health & $46.6(17.5)$ & $-0.150(0.097)$ \\
\hline Vitality & $46.0(26.6)$ & $-0.199(0.027)$ \\
\hline Social functioning & $57.4(28.2)$ & $-0.270(0.002)$ \\
\hline Role-emotional & $61.8(48.0)$ & $-0.269(0.003)$ \\
\hline Mental health & $51.9(24.5)$ & $-0.146(0.105)$ \\
\hline
\end{tabular}

Note: $r$, Pearson's correlation coefficient.

Abbreviations: DM, diabetes mellitus; SF-36, Medical Outcomes Study 36-Item Short-Form Health Survey; SD, standard deviation. other treatment regimens, except in terms of role-physical. Intensively treated type 1 patients tended to have better HRQoL than patients on other treatment regimens, except in terms of social functioning and role-emotional.

An increased duration of DM (measured according to the categories presented in Table 1) was associated with lower HRQoL in terms of physical functioning $\left(r_{s}=-0.271\right.$, $P=0.002)$, role-physical $\left(r_{s}=-0.209, P=0.020\right)$, general health $\left(r_{s}=-0.372, P<0.001\right)$, vitality $\left(r_{s}=-0.312, P<0.001\right)$, role-emotional $\left(r_{s}=-0.224, P=0.012\right)$, and mental health $\left(r_{s}=-0.197, P=0.028\right)$. In terms of social functioning, there was a tendency in the same direction; however, it did not reach statistical significance $\left(r_{s}=-0.160, P=0.077\right)$. Regarding bodily pain dimension, it seemed to exist no relationship with duration of disease $\left(r_{s}=-0.045, P=0.621\right)$.

Table 4 Health-related quality of life in patients with diabetes mellitus and their sex

\begin{tabular}{|c|c|c|c|}
\hline \multirow{3}{*}{$\begin{array}{l}\text { SF-36 dimensions } \\
\text { (adjusted for age) }\end{array}$} & \multicolumn{3}{|l|}{ Sex } \\
\hline & \multirow{2}{*}{$\frac{\text { Male }}{\text { Mean (SD) }}$} & \multirow{2}{*}{$\frac{\text { Female }}{\text { Mean (SD) }}$} & \multirow[t]{2}{*}{$P$-value } \\
\hline & & & \\
\hline Physical functioning & $11.2(33.7)$ & $-13.6(21.6)$ & $<0.001$ \\
\hline Role-physical & $6.9(47.2)$ & $-8.4(44.8)$ & 0.067 \\
\hline Bodily pain & $5.0(31.9)$ & $-6.1(31.6)$ & 0.054 \\
\hline General health & $3.2(15.5)$ & $-3.9(18.6)$ & 0.022 \\
\hline Vitality & $6.5(28.1)$ & $-7.9(21.0)$ & 0.001 \\
\hline Social functioning & $7.2(25.2)$ & $-8.7(27.1)$ & $<0.001$ \\
\hline Role-emotional & I4.I (43.0) & $-17.2(44.6)$ & $<0.001$ \\
\hline Mental health & $5.8(23.5)$ & $-7.0(23.3)$ & 0.003 \\
\hline
\end{tabular}

Abbreviations: SF-36, Medical Outcomes Study 36-Item Short-Form Health Survey; SD, standard deviation. 
Table 5 Health-related quality of life in patients with diabetes mellitus and body mass index

\begin{tabular}{|c|c|c|c|c|}
\hline \multirow{3}{*}{$\begin{array}{l}\text { SF-36 dimensions } \\
\text { (adjusted for age) }\end{array}$} & \multicolumn{4}{|c|}{ Body mass index category $\left(\mathrm{kg} / \mathrm{m}^{2}\right)$} \\
\hline & \multirow{2}{*}{$\frac{|8.5 \leq \mathrm{BM}|<25.0}{\text { Mean }(\mathrm{SD})}$} & \multirow{2}{*}{$\frac{25.0 \leq \mathrm{BMI}<30.0}{\text { Mean }(\mathrm{SD})}$} & \multirow{2}{*}{$\frac{B M I \geq 30.0}{\text { Mean (SD) }}$} & \multirow[t]{2}{*}{ P-value } \\
\hline & & & & \\
\hline Physical & $7.9(29.3)^{a *}$ & $8.0(34.9)^{\text {a* }}$ & $-14.4(23.4)^{\mathrm{b} *}$ & $<0.001$ \\
\hline \multicolumn{5}{|l|}{ functioning } \\
\hline Role-physical & $1.6(50.0)$ & $-6.9(42.1)$ & $-1.8(47.6)$ & 0.203 \\
\hline Bodily pain & $3.6(29.5)$ & $\mathrm{I} .3(33.7)$ & $-4.2(32.6)$ & 0.540 \\
\hline General health & I.I (I4.9) & $0.9(17.6)$ & $-1.8(18.8)$ & 0.703 \\
\hline Vitality & $6.9(26.1)^{a *}$ & $2.3(25.4)^{\mathrm{a}, \mathrm{b} *}$ & $-7.8(25.3)^{b *}$ & 0.034 \\
\hline Social functioning & $2.9(30.1)$ & $3.6(26.2)$ & $-6.1(25.2)$ & 0.182 \\
\hline Role-emotional & $6.3(39.1)$ & $2.2(48.2)$ & $-7.2(49.3)$ & 0.414 \\
\hline Mental health & $6.9(21.2)$ & $-3.4(22.9)$ & $-1.8(27.0)$ & 0.143 \\
\hline
\end{tabular}

Note: *Presence of the same letter $\left(^{a, b}\right)$ in superscript indicates absence of significant differences in post hoc tests.

Abbreviations: SF-36, Medical Outcomes Study 36-Item Short-Form Health Survey; SD, standard deviation.

\section{Discussion}

Demographic and clinical variables in patients with DM were related to HRQoL, regardless of age. Globally, we highlight physical functioning and vitality as the dimensions more related to these variables. The adjustment of SF-36 scores for age may obscure relationships between several clinical variables and HRQoL dimensions that strongly depend on a concomitant relationship with age. Therefore, absolute scores on the SF-36 and their relationship with clinical variables may have clinical usefulness, but to analyze their direct effect on HRQoL, which was our intention, it is recommended that values are adjusted for age.

Our results showed that being female was related to worse HRQoL in terms of physical functioning, general health, vitality, social functioning, role-emotional, and mental health, and a tendency in the same direction in terms of role-physical and bodily pain. These findings are partially in agreement with those of Kleefstra et al, Neves et al, and Papadopoulos et al, ${ }^{21-23}$ who found that diabetic females reported, respectively: lower HRQoL in all dimensions of
SF-36 with the exception of the general health dimension; in physical functioning, bodily pain, vitality, and mental health of SF-36; and in all dimensions of the aforementioned instrument. Conversely, some studies ${ }^{7,19,20,25,33}$ found no relationship between sex and HRQoL. Different explanations for the worse HRQoL of women with DM have been presented: females have an increased risk of developing cardiovascular disease, ${ }^{48}$ being hypertensive, obese, having more symptoms related to hyperglycemia, ${ }^{49}$ presenting higher prevalence rates of depression, ${ }^{31,50}$ anxiety, having less energy, ${ }^{31}$ and presenting greater difficulty in doing physical exercise, ${ }^{50}$ and this factor may lead to worse HRQoL, particularly in some dimensions. An alternative explanation may be the fact that women find themselves overburdened with several competing demands, such as their commitments toward their closest relatives, as well as with their jobs and household activities, whereas men are more concentrated in their paid jobs, which may contribute to greater physical and psychological overload. ${ }^{51}$ These above-mentioned sex patterns with regard to work roles were observed across countries. It is worth noticing that in

Table 6 Health-related quality of life and type of diabetes mellitus and treatment regimens

\begin{tabular}{|c|c|c|c|c|c|}
\hline \multirow{3}{*}{$\begin{array}{l}\text { SF-36 dimensions } \\
\text { (adjusted for age) }\end{array}$} & \multicolumn{2}{|c|}{ Type I diabetes mellitus } & \multicolumn{2}{|c|}{ Type 2 diabetes mellitus } & \multirow[t]{3}{*}{$P$-value } \\
\hline & Conventional & Intensive & Without insulin & With insulin & \\
\hline & Mean (SD) & Mean (SD) & Mean (SD) & Mean (SD) & \\
\hline Physical functioning & $1.0(36.4)^{\mathrm{a}, \mathrm{b} *}$ & $10.4(14.9)^{\mathrm{a}, \mathrm{b} *}$ & $7.2(34.2)^{\text {a* }}$ & $-11.3(27.3)^{b *}$ & 0.016 \\
\hline Role-physical & $-10.2(56.0)$ & $12.3(39.4)$ & $8.2(48.2)$ & $-9.5(42.4)$ & 0.163 \\
\hline Bodily pain & $4.8(33.3)$ & I5.I (20.0) & $-1.8(33.9)$ & $-4.1(32.1)$ & 0.231 \\
\hline General health & $-1.7(18.1)$ & $8.4(13.6)$ & $1.7(17.6)$ & $-4.0(17.0)$ & 0.093 \\
\hline Vitality & $-0.5(28.7)^{\mathrm{a}, \mathrm{b} *}$ & $9.4(23.3)^{\mathrm{a}, \mathrm{b} *}$ & $6.2(26.2)^{a *}$ & $-9.4(23.6)^{\mathrm{b} *}$ & 0.012 \\
\hline Social functioning & $7.4(31.1)$ & $7.4(23.7)$ & I.4 (25.8) & $-6.0(27.9)$ & 0.214 \\
\hline Role-emotional & II.I (37.5) & $2.9(28.6)$ & $4.6(48.1)$ & $-9.2(50.3)$ & 0.367 \\
\hline Mental health & $4.8(27.6)$ & $8.2(17.9)$ & $0.6(23.7)$ & $-4.6(25.1)$ & 0.282 \\
\hline
\end{tabular}

Note: *Presence of the same letter $\left(^{a, b}\right)$ in superscript indicates absence of significant differences in post hoc tests.

Abbreviations: SF-36, Medical Outcomes Study 36-Item Short-Form Health Survey; SD, standard deviation. 
our study women showed the longest duration of DM and a higher prevalence of obesity, which may act as confounders contributing to the worse HRQoL. On the other hand, the relationships between age and some clinical variables, namely the type of DM and BMI, highlight the relevance of age-adjustment to the HRQoL scores.

Although Mier et $\mathrm{al}^{36}$ reported no relationship between obesity in type $2 \mathrm{DM}$ and HRQoL, we found that obese patients assessed their HRQoL as being worse than normal and overweight individuals in terms of physical functioning. It was previously shown that an increasing BMI in type 2 DM was related to lower physical functioning, ${ }^{20,21,23,34}$ as well as in worse HRQoL in other dimensions of the SF-36: role-physical, ${ }^{20,21}$ bodily pain, ${ }^{21}$ general health, ${ }^{34}$ social functioning, ${ }^{21,34}$ and role-emotional. ${ }^{20}$ We also emphasize that obese patients had lower vitality than their normal weight counterparts. However, as far as we know, we found no study reporting that obese diabetic patients had worse HRQoL in this particular dimension in comparison with normal and overweight ones. A possible explanation for the worse physical functioning and vitality in obese patients may be related to the coexistence of hypertension or other chronic morbidities in this group of patients.

While Wexler et al and Caldwell et al ${ }^{17,26}$ did not observe any relationship between treatment regimens in type $2 \mathrm{DM}$ and HRQoL, we observed that insulin therapy in type 2 DM was related to lower scores on the physical functioning dimension compared with those who were on oral hypoglycemic agents, in accordance with previous research. ${ }^{18,19,34}$ Moreover, Johnson et $\mathrm{al}^{19}$ reported that insulin use in type 2 DM was related to worse HRQoL in terms of role-physical, general health, and social functioning. Interestingly, Fal et $\mathrm{al}^{7}$ observed that patients with type 2 diabetes on insulin therapy had worse HRQoL in the somatic and environmental domains and better HRQoL in the psychological domain than those receiving oral hypoglycemic agents. Additionally, we found that type 2 diabetic patients treated with insulin showed poorer vitality than type 2 patients not treated with insulin therapy. Nevertheless, to our knowledge, there are no studies reporting that insulin use is related to worse HRQoL for this specific dimension in type 2 diabetic patients. Different explanations have been put forward by various authors to explain the lower HRQoL in patients requiring insulin to achieve better metabolic control: the side effects of the medication and its influence on scheduling and organizing their daily activities, ${ }^{7}$ the fear of weight gain, and concerns about the impact of the insulin regimen on their social environment. ${ }^{52}$ Alternative explanations for these findings in such patients may be the longer duration of the disease, a sense of frustration after failure of oral medications, or the onset of diabetes-related complications and subsequent necessity to start insulin. Patients commonly held erroneous and irrational beliefs about the relationship of the need of insulin therapy and the development of chronic complications of DM. Subcutaneous insulin injection is also often considered as an intrusive regimen by patients. These hypotheses should be tested in future research, on the one hand using larger samples allowing multivariate analysis, and on the other hand by qualitative studies focusing on the personal representations of different features of treatment regimens.

In our study, there were no differences on any of the HRQoL dimensions between type 1 patients on a conventional regimen and those on an intensive insulin regimen, which is consistent with the results obtained by Eiser et $\mathrm{al}^{43}$ but different from the findings of Neves et al, ${ }^{22}$ who found better HRQoL in terms of physical functioning and vitality in type 1 patients on an intensive insulin regimen. Eventually, the absence of differences in terms of HRQoL between insulin treatment regimens in type $1 \mathrm{DM}$ may be related to the small number of patients interviewed.

Some studies did not find a relationship between duration of diabetes and HRQoL in type $2 \mathrm{DM}^{7,12,16,26,33}$ or in type 1 DM, ${ }^{33}$ and another study ${ }^{43}$ reported better HRQoL in terms of diabetes satisfaction with increasing duration of the disease in young adults with type 1 DM. In contrast, across both type 1 and type 2 patient groups, we found a negative association between duration of diabetes and HRQoL in terms of physical functioning, role-physical, general health, vitality, role-emotional and mental health, and a tendency in the same direction in terms of social functioning. These results, on one hand, are partially overlapping with the findings of Neves et al, ${ }^{22}$ since in that study an increased duration of DM was related to lower HRQoL in all dimensions of the SF-36, but on the other hand partially agree with the findings of Kalda et al, Papadopoulos et al, and Mier et al, ${ }^{20,23,36}$ who found that a longer duration of diabetes was related to worse general health, vitality, social functioning, ${ }^{20,23}$ bodily pain, ${ }^{23}$ mental health, ${ }^{20}$ and physical component. ${ }^{36}$ Possible explanations for this reduction in HRQoL for diabetic patients with a longer duration of disease may be related to the sharp decrease of energy, vitality, and social relationships, the development of long-term complications of DM in the later stages of the disease, and consequently to the intensification and complexity of the treatment regimen. ${ }^{20} \mathrm{It}$ is worth noticing that, by comparing age-adjusted HRQoL scores, the relationship found between duration of diabetes 
and HRQoL is not due to the older age of patients, but to the longer duration of DM.

The difference in the results between this study and others may be explained, on the one hand, by the different generic tools used to assess HRQoL, which do not measure exactly the same dimensions, and by the fact that some studies have evaluated only type 1 or type 2 diabetic patients, whereas in the present study both types of patients were included. Given the frequent age difference between patients with type 1 diabetes and those with type 2 diabetes, and due to the fact that not all studies make the age-adjustment of the values of the generic instruments to assess HRQoL for this variable, we highlight the implications for clinical practice when HRQoL is evaluated considering age-adjusted values.

Several limitations of this study should be considered when interpreting its results. The results would be more robust with a larger sample. Further, most of the patients interviewed were of low sociocultural status, which may have limited their understanding of the questions in the instrument used to assess HRQoL. Generalization of our findings may be limited because our sample was collected in a central public hospital and might not be representative of the diabetic population in other care centers or in primary care. Further investigations are warranted to adjust the dimensions of HRQoL to other variables (eg, sex, BMI, type of DM and treatment regimens, and disease duration) to explore the relationships between HRQoL and the demographic and clinical variables considered, we think may explain some of these relationships. Further studies are needed to explore the relationships between demographic and clinical variables. As previously stated, the use of qualitative methodology could be useful to obtain information complementary to that achieved by quantitative studies, allowing more accurate interpretation of some results. Finally, participants' self-reported duration of diabetes, and height and weight values when calculating BMI might not be as reliable as measurements taken from official medical records.

One of the main points of our results is the relationship found between the vitality dimension of the SF-36 and obesity and insulin use in patients with type 2 DM. To our knowledge, there are no studies providing such data (ie, reporting the negative impact of these two factors on this specific dimension of HRQoL), which seems worthy of exploring further. Apart from the reasons previously stated, adjusting HRQoL values for age is important, since type 1 patients are significantly younger than those with type 2 diabetes, and our analysis allowed us to analyze and compare these two groups without the confounding effect of age.

\section{Conclusion}

Our findings suggest that being female, obese, having type 2 DM and taking insulin, and having diabetes for a longer period of time are characteristics associated with worse ageadjusted HRQoL in patients with DM. Globally, physical functioning and vitality were the dimensions more related to these demographic and clinical variables.

\section{Disclosure}

The authors report no conflicts of interest in this work.

\section{References}

1. International Diabetes Federation. IDF Diabetes Atlas. 6th ed. Brussels, Belgium: International Diabetes Federation; 2013.

2. Yang $\mathrm{W}, \mathrm{Lu} \mathrm{J}$, Weng J, et al. Prevalence of diabetes among men and women in China. N Engl J Med. 2010;362:1090-1101.

3. Zhang J, Yang Z, Xiao J, et al. Association between family history risk categories and prevalence of diabetes in Chinese population. PLoS One. 2015;10:e0117044.

4. Zeng B, Sun W, Gary RA, Li C, Liu T. Towards a conceptual model of diabetes self-management among Chinese immigrants in the United States. Int J Environ Res Public Health. 2014;11:6727-6742.

5. Gardete-Correia L, Boavida JM, Raposo JF, et al. First diabetes prevalence study in Portugal: PREVADIAB study. Diabet Med. 2010;27: 879-881.

6. Ahola AJ, Saraheimo M, Forsblom C, Hietala K, Sintonen H, Groop PH. Health-related quality of life in patients with type 1 diabetes association with diabetic complications (the FinnDiane Study). Nephrol Dial Transplant. 2010;25:1903-1908.

7. Fal AM, Jankowska B, Uchmanowicz I, Sen M, Panaszek B, Polanski J. Type 2 diabetes quality of life patients treated with insulin and oral hypoglycemic medication. Acta Diabetol. 2011;48:237-242.

8. Snoek FJ. Quality of life: a closer look at measuring patients' well-being. Diabetes Spectr. 2000;13:24-28.

9. Rubin RR. Diabetes and quality of life. Diabetes Spectr. 2000;13: $21-23$.

10. Glasgow RE, Fisher EB, Anderson BJ, et al. Behavioral science in diabetes. Contributions and opportunities. Diabetes Care. 1999;22: 832-843.

11. Burroughs TE, Desikan R, Waterman BM, Gilin D, McGill J. Development and validation of the Diabetes Quality of Life Brief Clinical Inventory. Diabetes Spectr. 2004;17:41-49.

12. Andayani TM, Ibrahim MIM, Asdie AH. The association of diabetesrelated factor and quality of life in type 2 diabetes mellitus. Int J Pharm Pharm Sci. 2010;2:139-145.

13. Sakamaki H, Ikeda S, Ikegami N, et al. Measurement of HRQL using EQ-5D in patients with type 2 diabetes mellitus in Japan. Value Health. 2006;9:47-53.

14. Rubin RR, Peyrot M. Quality of life and diabetes. Diabetes Metab Res Rev. 1999;15:205-218.

15. Lee WJ, Song KH, Noh JH, Choi YJ, Jo MW. Health-related quality of life using the EuroQol 5D questionnaire in Korean patients with type 2 diabetes. J Korean Med Sci. 2012;27:255-260.

16. Redekop WK, Koopmanschap MA, Stolk RP, Rutten GE, Wolffenbuttel BH, Niessen LW. Health-related quality of life and treatment satisfaction in Dutch patients with type 2 diabetes. Diabetes Care. 2002;25:458-463.

17. Wexler DJ, Grant RW, Wittenberg E, et al. Correlates of health-related quality of life in type 2 diabetes. Diabetologia. 2006;49:1489-1497.

18. Camacho F, Anderson RT, Bell RA, et al. Investigating correlates of health related quality of life in a low-income sample of patients with diabetes. Qual Life Res. 2002;11:783-796. 
19. Johnson JA, Nowatzki TE, Coons SJ. Health-related quality of life of diabetic Pima Indians. Med Care. 1996;34:97-102.

20. Kalda R, Rätsep A, Lember M. Predictors of quality of life of patients with type 2 diabetes. Patient Prefer Adherence. 2008;2:21-26.

21. Kleefstra N, Ubink-Veltmaat LJ, Houweling ST, Groenier KH, Meyboom-de Jong B, Bilo HJ. Cross-sectional relationship between glycaemic control, hyperglycaemic symptoms and quality of life in type 2 diabetes (ZODIAC-2). Neth J Med. 2005;63:215-221.

22. Neves C, Carvalheiro M, Ferreira PL. [Quality of life in people with diabetes mellitus]. Arq Med. 2002;16:200-210. Portuguese.

23. Papadopoulos AA, Kontodimopoulos N, Frydas A, Ikonomakis E, Niakas D. Predictors of health-related quality of life in type II diabetic patients in Greece. BMC Public Health. 2007;7:186.

24. Quah JH, Luo N, Ng WY, How CH, Tay EG. Health-related quality of life is associated with diabetic complications, but not with short-term diabetic control in primary care. Ann Acad Med Singapore. 2011;40: 276-286.

25. Ucan O, Ovayolu N. Relationship between diabetes mellitus, hypertension and obesity, and health-related quality of life in Gaziantep, a central south-eastern city in Turkey. J Clin Nurs. 2010;19:2511-2519.

26. Caldwell EM, Baxter J, Mitchell CM, Shetterly SM, Hamman RF. The association of non-insulin-dependent diabetes mellitus with perceived quality of life in a biethnic population: the San Luis Valley Diabetes Study. Am J Public Health. 1998;88:1225-1229.

27. Trief PM, Wade MJ, Pine D, Weinstock RS. A comparison of healthrelated quality of life of elderly and younger insulin-treated adults with diabetes. Age Ageing. 2003;32:613-618.

28. Rejeski WJ, Lang W, Neiberg RH, et al. Correlates of health-related quality of life in overweight and obese adults with type 2 diabetes. Obesity (Silver Spring). 2006;14:870-883.

29. Schunk M, Reitmeir P, Schipf S, et al. Health-related quality of life in subjects with and without type 2 diabetes: pooled analysis of five populationbased surveys in Germany. Diabet Med. 2012;29:646-653.

30. Árcega-Domínguez A, Lara-Muñoz C, Ponce-De-León-Rosales S. [Factors related to subjective evaluation of quality of life of diabetic patients]. Rev Invest Clin. 2005;57:676-684. Spanish.

31. Eiser JR, Riazi A, Eiser C, Hammersley S, Tooke JE. Predictors of psychological well-being in types 1 and 2 diabetes. Psychol Health. 2001;16:99-110.

32. Javanbakht M, Abolhasani F, Mashayekhi A, Baradaran HR, Jahangiri Noudeh Y. Health related quality of life in patients with type 2 diabetes mellitus in Iran: a national survey. PLoS One. 2012;7:e44526.

33. Jacobson AM, de Groot M, Samson JA. The evaluation of two measures of quality of life in patients with type I and type II diabetes. Diabetes Care. 1994;17:267-274.

34. Hill-Briggs F, Gary TL, Hill MN, Bone LR, Brancati FL. Health-related quality of life in urban African Americans with type 2 diabetes. $J$ Gen Intern Med. 2002;17:412-419.

35. Mena Martín FJ, Martín Escudero JC, Simal Blanco F, Bellido Casado J, Carratero Ares JL. [Type 2 diabetes mellitus and health-related quality of life: results from the Hortega Study]. An Med Interna. 2006;23:357-360. Spanish.
36. Mier N, Bocanegra-Alonso A, Zhan D, Zuniga MA, Acosta RI. Healthrelated quality of life in a binational population with diabetes at the Texas-Mexico border. Rev Panam Salud Publica. 2008;23:154-163.

37. Maciejewski ML, Patrick DL, Williamson DF. A structured review of randomized controlled trials of weight loss showed little improvement in health-related quality of life. J Clin Epidemiol. 2005;58:568-578.

38. Warkentin LM, Das D, Majumdar SR, Johnson JA, Padwal RS. The effect of weight loss on health-related quality of life: systematic review and meta-analysis of randomized trials. Obes Rev. 2014;15:169-182.

39. Issa BA, Baiyewu O. Quality of life of patients with diabetes mellitus in a Nigerian teaching hospital. Hong Kong J Psychiatry. 2006;16:27-33.

40. Solli O, Stavem K, Kristiansen IS. Health-related quality of life in diabetes: the associations of complications with EQ-5D scores. Health Qual Life Outcomes. 2010;8:18.

41. Imayama I, Plotnikoff RC, Courneya KS, Johnson JA. Determinants of quality of life in adults with type 1 and type 2 diabetes. Health Qual Life Outcomes. 2011;9:115.

42. Huang IC, Liu JH, Wu AW, Wu MY, Leite W, Hwang CC. Evaluating the reliability, validity and minimally important difference of the Taiwanese version of the diabetes quality of life (DQOL) measurement. Health Qual Life Outcomes. 2008;6:87.

43. Eiser C, Flynn M, Green E, et al. Quality of life in young adults with type 1 diabetes in relation to demographic and disease variables. Diabet Med. 1992;9:375-378.

44. Wändell PE. Quality of life of patients with diabetes mellitus. An overview of research in primary health care in the Nordic countries. Scand J Prim Health Care. 2005;23:68-74.

45. World Health Organization. Obesity: preventing and managing the global epidemic. Report of a WHO consultation on obesity. Geneva, Switzerland: World Health Organization; 1998. Available from: http:// whqlibdoc.who.int/hq/1998/WHO_NUT_NCD_98.1_\%28p1-158\%29. pdf. Accessed March 6, 2015.

46. Ferreira PL. [Development of the Portuguese version of MOS SF-36. Part I - Cultural and linguistic adaptation]. Acta Med Port. 2000;13:55-66. Portuguese.

47. Ferreira PL. [Development of the Portuguese version of MOS SF-36. Part II - Validation tests]. Acta Med Port. 2000;13:119-127. Portuguese.

48. Norhammar A, Schenck-Gustafsson K. Type 2 diabetes and cardiovascular disease in women. Diabetologia. 2013;56:1-9.

49. Legato MJ, Gelzer A, Goland R, et al. Gender-specific care of the patient with diabetes: review and recommendations. Gend Med. 2006;3: 131-158.

50. Zuberi SI, Syed EU, Bhatti JA. Association of depression with treatment outcomes in type 2 diabetes mellitus: a cross-sectional study from Karachi, Pakistan. BMC Psychiatry. 2011;11:27.

51. Gjerdingen D, McGovern P, Bekker M, Lundberg U, Willemsen T. Women' work roles and their impact on health, well-being, and career: comparisons between the United States, Sweden, and The Netherlands. Women Health. 2000;31:1-20.

52. Pouwer F, Hermanns N. Insulin therapy and quality of life: a review. Diabetes Metab Res Rev. 2009;25 Suppl 1:S4-S10.

\section{Publish your work in this journal}

Diabetes, Metabolic Syndrome and Obesity: Targets and Therapy is an international, peer-reviewed open-access journal committed to the rapid publication of the latest laboratory and clinical findings in the fields of diabetes, metabolic syndrome and obesity research. Original research, review, case reports, hypothesis formation, expert opinion and commentaries are all considered for publication. The manuscript management system is completely online and includes a very quick and fair peer-review system, which is all easy to use. Visit $\mathrm{http}: / /$ www.dovepress.com/testimonials.php to read real quotes from published authors. 